\title{
Vaginal Cuff
}

National Cancer Institute

\section{Source}

National Cancer Institute. Vaginal Cuff. NCI Thesaurus. Code C88207.

The part of the apical portion of the vagina which is closed with sutures following total hysterectomy. 